\title{
Cervico-mediastinal schwannoma of the vagus nerve: resection with intraoperative nerve monitoring
}

\section{Updates in Surgery}

Official Journal of the Italian Society of Surgery

ISSN 2038-131X

Volume 63

Number 1

Updates Surg (2010) 63:59-61 DOI $10.1007 /$

s13304-010-0040-9

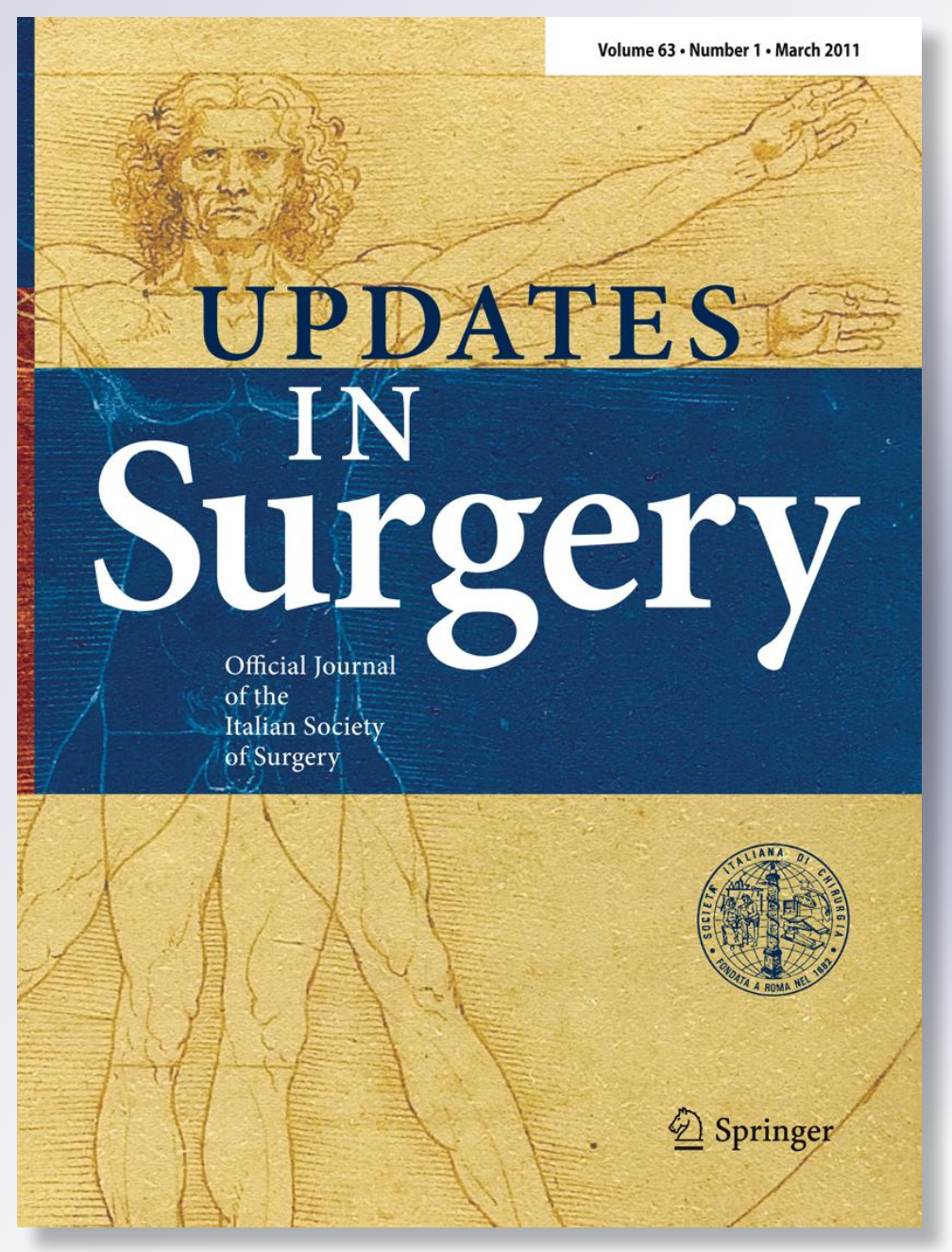

望 Springer 
Your article is protected by copyright and all rights are held exclusively by SpringerVerlag. This e-offprint is for personal use only and shall not be self-archived in electronic repositories. If you wish to self-archive your work, please use the accepted author's version for posting to your own website or your institution's repository. You may further deposit the accepted author's version on a funder's repository at a funder's request, provided it is not made publicly available until 12 months after publication. 


\title{
Cervico-mediastinal schwannoma of the vagus nerve: resection with intraoperative nerve monitoring
}

\author{
Andrea Imperatori · Gianlorenzo Dionigi • \\ Lavinia De Monte $\cdot$ Valentina Conti • \\ Nicola Rotolo
}

Received: 4 November 2010/ Accepted: 16 December 2010/Published online: 6 January 2011

(C) Springer-Verlag 2010

\begin{abstract}
Schwannomas are usually benign, single, encapsulated, slow-growing tumours originating from cranial or spinal nerve sheaths. The vagus nerve involvement at the mediastinal inlet is very uncommon. For anatomical reasons, the resection of cervical and mediastinal schwannoma of the vagus nerve has a high risk of vocal fold paralysis. We describe the case of a 67-year-old female with a cervico-mediastinal schwannoma of the vagus nerve that we removed using the intraoperative neuromonitoring technique. The patient presented with mild hoarseness and complained of discomfort behind the jugular notch. Neck and chest computerized tomography described a $35 \times 30 \mathrm{~mm}$ solid lesion behind the left clavi-sternal junction; preoperative fine needle aspiration cytology revealed schwannoma. Resection of the mass was performed with a cervical approach and the vagus nerve tumour was completely removed under continuous neuromonitoring (NIM-3 ${ }^{\circledR}$ System), preserving the vagus and the recurrent laryngeal nerve function. Pathology on the resected mass documented A-type schwannoma with "ancient schwannoma" areas. The intraoperative neurostimulation and neuromonitoring approach for the resection of vagus schwannoma are recommended because it may reduce the risk of injury to the vagus and to the recurrent laryngeal nerve.
\end{abstract}

Keywords Schwannoma - Cervical-mediastinal . Vagus nerve - Intraoperative nerve monitoring · Recurrent laryngeal nerve

A. Imperatori $(\bowtie) \cdot$ G. Dionigi · L. De Monte ·

V. Conti $\cdot$ N. Rotolo

Department of Surgical Sciences and Center for Thoracic

Surgery, University of Insubria, Ospedale di Circolo,

Viale Borri 57, 2100 Varese, Italy

e-mail: andrea.imperatori@uninsubria.it

\section{Introduction}

Schwannomas (neurinomas, neurilemmomas) are usually benign, single, encapsulated, slow-growing tumours that in about $25 \%$ of cases occur in the head and neck. The vagus nerve involvement is uncommon, less than 100 cases having been described in the literature [1,2]. Cervical schwannomas are typically diagnosed in the 3rd-5th decade of life, without sex predominance [3]. They usually present as a palpable bulge in the neck, slow-growing and painless. Large schwannomas may cause dysphagia, hoarseness or dyspnoea by the compression of adjacent structures in the neck [4]. The chest computed tomography (CT) findings are those of a parapharyngeal or paratracheal mass with smooth border and relatively homogeneous structure. Because clinical and CT findings are non-specific, differential diagnosis with other cervical masses is necessary [2]. Definitive diagnosis is best achieved by needle biopsy; surgery is the treatment of choice for these tumours. Resection of schwannomas localized at the cervico-mediastinal junction may be technically challenging, in order to avoid injury to the vagus and to the recurrent laryngeal nerve [5].

We describe the case of a vagus nerve schwannoma located at the cervico-mediastinal inlet, that we resected using intraoperative nerve monitoring in order to decrease the risk of recurrent laryngeal nerve paralysis.

\section{Case report}

A 67-year-old female with a history of arterial hypertension, hiatal hernia and hypothyroidism, presented with symptoms of episodic hoarseness and mild discomfort localized under the jugular notch. Physical examination 


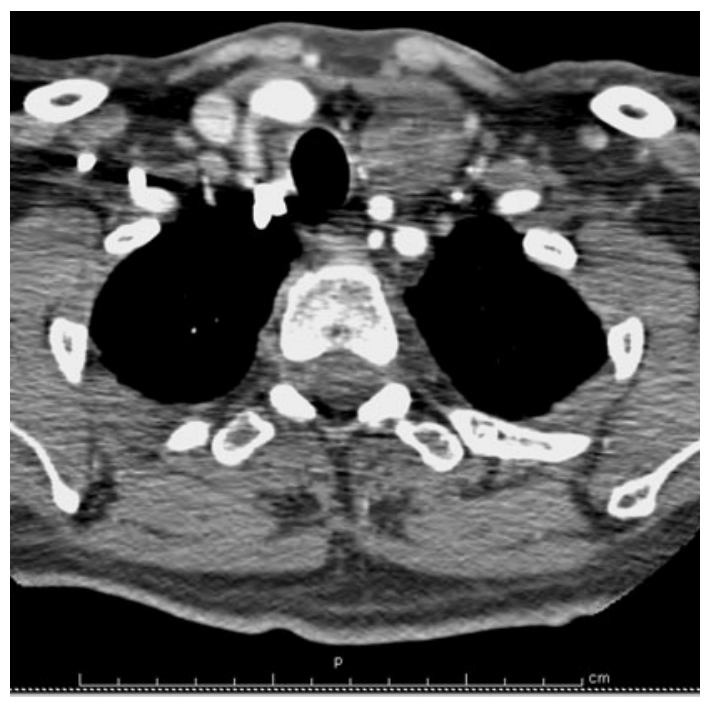

Fig. 1 Computed tomography contrast enhanced scan showing a round mass with smooth margins adjacent to the left aspect of the trachea and overlying the common carotid artery

revealed a smooth-surfaced and painless soft mass under the left sterno-clavicular junction. Ultrasonography and CT-scan described a $35 \times 30 \mathrm{~mm}$ solid lesion with welldefined and vascularised margin, adjacent to the left aspect of the trachea at the cervical-thoracic transition point (Fig. 1). Ultrasonography-guided fine needle aspiration cytology (FNAC) with immuno-stain, performed in a hospital in France, revealed benign nerve cells suggestive of schwannoma. Preoperative laryngoscopy revealed normal motility of the vocal cords.

Surgical resection of the mass was performed with cervical suprasternal access. Briefly, the tumour was freed from adhesions with the internal jugular vein and the carotid sheath was dissected. The vagus nerve was identified as the structure from which the tumour originated. The mass was isolated from the vagus nerve and was dissected free from adhesions with the trachea and with the common carotid artery. Meanwhile, intraoperative recurrent laryngeal nerve monitoring was performed by stimulating the vagus nerve proximally to the lesion with the nerve integrity monitor (NIM-3 ${ }^{\circledR}$ System), in order to prevent injury of vagus and recurrent laryngeal nerves $[6,7]$. The neurostimulator settings were: intensity, $1 \mathrm{~mA}$; pre-resection vagus nerve signal, $800 \mu \mathrm{V}$. Excision of the schwannoma was completed with preservation of the vagus and of the left recurrent laryngeal nerve function, confirmed by unchanged proximal vagus nerve signal. The resected specimen consisted of an ovoid-shaped yellowish mass, partially excavated in the centre (Fig. 2). Histology documented A-type schwannoma with "ancient schwannoma" areas. The postoperative course was uneventful. Laryngoscopy revealed normally functioning vocal folds and the patient was discharged on the third postoperative day.

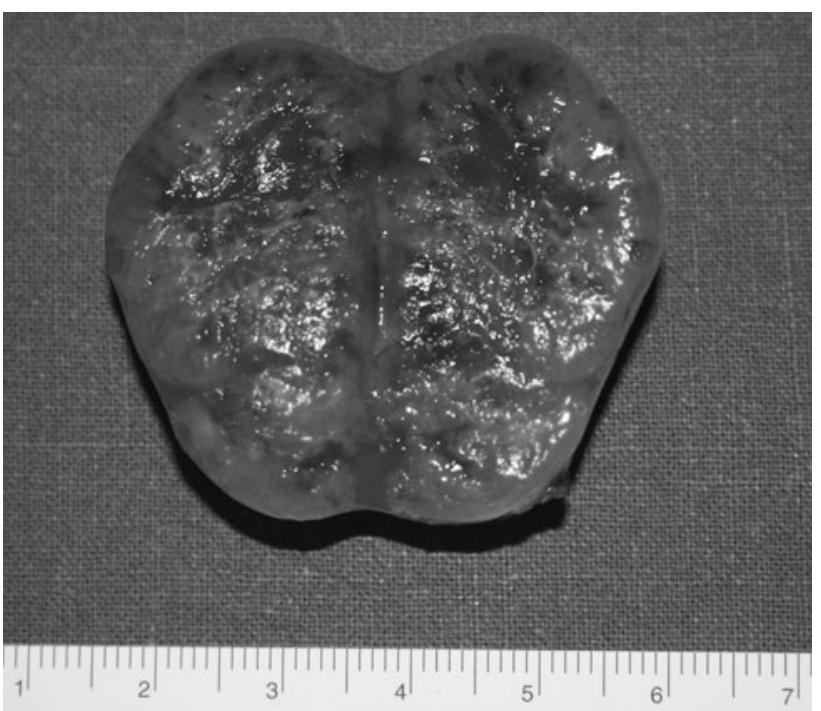

Fig. 2 Cut surface of the resected schwannoma, oval shaped, measuring $35 \times 30 \mathrm{~mm}$

\section{Discussion}

Vagus nerve primary tumours are uncommon and their localization at the cervico-mediastinal transition point is extremely rare. Only a few cases of cervico-mediastinal and mediastinal schwannomas have been described, some of them being malignant [8-10]. Cervical schwannomas clinically present as asymptomatic slow-growing lateral neck masses palpable along the medial border of the sternocleidomastoid muscle [11]. Preoperative diagnosis is difficult because vagal schwannomas typically do not cause neurological deficits. Therefore, several differential diagnoses for tumour of the neck must be considered, including paraganglioma, branchial cleft cyst, malignant lymphoma, metastatic cervical lymphadenopathy and thyroid mass.

The usefulness of preoperative diagnosis by FNAC is controversial. If the cervical mass can be ruled out to be malignant, based on clinical and imaging findings, many authors do not recommend open or needle biopsy, because the treatment of choice of the mass is surgical anyhow. For vagus nerve tumours, there is general agreement that treatment consists of complete surgical excision. For treatment of schwannoma the primary aim should be dissection of the tumour from the vagus, with preservation of the neural pathway. For anatomical reasons, the surgical resection of vagus nerve schwannoma carries a high risk of vocal fold paralysis, particularly if the tumour is adjacent to the trachea, or is located close to the jugular foramen, or is malignant $[11,12]$.

The schwannoma that we are presently reporting was localized at the cervical-mediastinal inlet, close to the trachea, and its resection presented two challenges: the choice of surgical approach (cervical vs. trans-thoracic) and the 
preservation of recurrent laryngeal nerve function. We chose the cervical approach because the mass was preoperatively documented benign by FNAC, therefore, it was likely to be mobilizable from the mediastinum, as it occurs with plongeant goiter. Moreover, the cervical approach allowed the successful implementation of intraoperative neuromonitoring by the NIM- $3{ }^{\circledR}$ System, a technique increasingly recommended to prevent laryngeal nerve injury [6, 7]. However, to prevent technical, anaesthesiology and anatomy pitfalls care must be taken in positioning the electrode accurately, since the adjustment of the head and neck after intubations can change the relative position of the tube and, hence, the electrode [13]. The use of a standardized approach to intraoperative neuromonitoring technology decrease the number of false and negative information and improve recurrent laryngeal nerve protection.

Conflict of interest The authors declare no conflicts of interest.

\section{References}

1. Conley JJ (1955) Neurogenic tumors in the neck. AMA Arch Otolaryngol 61:167-180

2. Mevio E, Gorini E, Sbrocca M, Artesi L, Mullace M, Castelli A, Migliorini L (2003) Unusual cases of cervical nerves schwannomas: phrenic and vagus nerve involvement. Auris Nasus Larynx 30:209-213. doi:10.1016/S0385-8146(03)00005-1

3. Weiss SW (1994) Hystological typing of soft tissue tumours. WHO official web site. http://www.whqlibdoc.who.int/publications/ 1994/3540567941_eng.pdf. Accessed 4 Nov 2010

4. Maebeya S, Miyoshi S, Fujiwara K, Sekii H, Suzuma T, Yosimasu T, Naito Y, Nishino E (1993) Malignant schwannoma of the intrathoracic vagus nerve: report of a case. Surg Today 23:1078-1080

5. Fujino K, Shinohara K, Aoki M, Hashimoto K, Omori K (2000) Intracapsular enucleation of vagus nerve-originated tumors for preservation of neural function. Otolaryngol Head Neck Surg 123:334-336

6. Barczyński M, Konturek A, Cichoń S (2009) Randomized clinical trial of visualization versus neuromonitoring of recurrent laryngeal nerves during thyroidectomy. Br J Surg 96:240-246. doi:10.1002/bjs.6417

7. Dionigi G, Boni L, Rovera F, Bacuzzi A, Dionigi R (2009) Neuromonitoring and video-assisted thyroidectomy: a prospective, randomized case-control evaluation. Surg Endosc 23:996-1003. doi:10.1007/s00464-008-0098-3

8. Fukai I, Masaoka A, Yamakawa Y, Niwa H, Eimoto T (1995) Mediastinal malignant epithelioid schwannoma. Chest 108:574-575. doi:10.1378/chest.108.2.574

9. Shoji F, Maruyama R, Okamoto T, Wataya H, Nishiyama K, Ichinose Y (2005) Malignant schwannoma of the upper mediastinum originating from the vagus nerve. World J Surg Oncol 3:65-68. doi:10.1186/1477-7819-3-65

10. Nakano CG, Massarollo LC, Volpi EM, Barbosa Junior JG, Arias V, Ueda RY (2008) Ancient schwannoma of the vagus nerve, resection with continuous monitoring of the inferior laryngeal nerve. Br J Otorhinolaryngol 74:316. doi:10.1590/S0034-72992008000200027

11. Colreavy MP, Lacy PD, Hughes J, Bouchier-Hayes D, Brennan P, O'Dwyer AJ, Donnelly MJ, Gaffney R, Maguire A, O'Dwyer TP, Timon CV, Walsh MA (2000) Head and neck schwannomas-a 10-year review. J Laryngol Otol 114:119-124

12. Chiofalo MG, Longo F, Marone U, Franco R, Petrillo A, Pezzullo L (2009) Cervical vagal schwannoma. A case report. Acta Otorhinolaryngol Ital 29:33-35

13. Dralle H, Sekulla C, Lorenz K, Brauckhoff M, Machens A, German IONM Study Group (2008) Intraoperative monitoring of the recurrent laryngeal nerve in thyroid surgery. World J Surg 32:1358-1366. doi:10.1007/s00268-008-9483-2 